\title{
Using accelerometry to quantify prey attack and handling behaviours in piscivorous pike Esox lucius
}

Deurs, Mikael van; Andersson, A.; Vinterstare, J.; Didenko, A.; Persson, A.; Brönmark, Christer; Nilsson, P.A.

Published in:

Journal of Fish Biology

Link to article, DOI:

$10.1111 / \mathrm{jfb} .13310$

Publication date:

2017

Document Version

Peer reviewed version

Link back to DTU Orbit

Citation (APA):

Deurs, M. V., Andersson, A., Vinterstare, J., Didenko, A., Persson, A., Brönmark, C., \& Nilsson, P. A. (2017).

Using accelerometry to quantify prey attack and handling behaviours in piscivorous pike Esox lucius. Journal of Fish Biology, 90(6), 2462-2469. https://doi.org/10.1111/jfb.13310

\section{General rights}

Copyright and moral rights for the publications made accessible in the public portal are retained by the authors and/or other copyright owners and it is a condition of accessing publications that users recognise and abide by the legal requirements associated with these rights.

- Users may download and print one copy of any publication from the public portal for the purpose of private study or research.

- You may not further distribute the material or use it for any profit-making activity or commercial gain

- You may freely distribute the URL identifying the publication in the public portal 


\section{BRIEF COMMUNICATION}

3 TITLE: Using accelerometry to quantify prey attack and handling behaviours in piscivorous pike 4 Esox lucius

6 AUTHORS: Mikael van Deurs ${ }^{1,2, *}$, Arne Andersson ${ }^{1}$, Jerker Vinterstare ${ }^{1}$, Alexander Didenko ${ }^{3}$

7 Anders Persson ${ }^{1}$, Christer Brönmark ${ }^{1}$ and P. Anders Nilsson ${ }^{1,4}$

AUTHOR AFFILIATION:

1. Department of Biology, Ecology Building, Lund University, SE-223 62 Lund, Sweden.

2. National Institute for Aquatic resources - Section for Marine Living Resources, Technical University of Denmark, Jægersborgs alle 1, DK-2920 Charlottenlund, Denmark.

3. Institute of Fisheries of the National Academy of Agrarian Sciences of Ukraine, Obukhivska St. 135, 03164 Kiev, Ukraine

4. Department of Environmental and Life Sciences - Biology, Karlstad University, SE-651 88, Karlstad, Sweden.

* Author to whom correspondence should be addressed: Mikael van Deurs, Tel: +45 51369380; email: mikael.van_deurs@biol.lu.se and $\underline{\text { mvd@aqua.dtu.dk }}$ 
21 KEY WORDS: accelerometer; Esox lucius; foraging; handling time; predation

23 ABSTRACT:

24 Predator-prey interactions play a central role in structuring aquatic food webs. Technical development that offers opportunities to observe predator behaviour also in the dark or in humic waters is therefore warranted. Here we use accelerometer technology to evaluate behaviours in the teleost ambush predator pike Esox lucius foraging on crucian carp. Automated rule-based estimates of prey-size determined handling time were obtained and are compared to video-recorded behaviours. Solutions to tag attachment and the limitations imposed by battery-time and datalogging capacities are evaluated.

\section{MANUSCRIPT:}

Piscivore predation plays a central role in structuring aquatic food webs (Kerfoot and Sih 1987, Carpenter and Kitchell, 1993). Predation is performed by individuals, and to bridge the order scales between individuals and systems, we need better identification of what factors and mechanisms influence behaviour and decision-making in individual predators (Fryxell and Lundberg, 1998). Fish are commonly apex predators in aquatic systems, but direct observation of their behaviour in nature is challenging (e.g. Jepsen et al. 2001). Studies are therefore commonly restricted to small scale laboratory settings (e.g. Nilsson et al., 2000), but even here the opportunity to make observations directly or by camera relies on sufficient visibility and proper light conditions (e.g. Jönsson et al., 2013). Studies on fish predator-prey interactions in darkness or in highly turbid or humic water are hence scarce for logistical reasons. Technical development however offers 
opportunities to quantify predator behaviours also in the absence of visual signals. For example, conventional telemetry techniques can aid the collection of positional data (Marsac \& Cayré, 1998), physiological telemetry techniques can monitor heart rate frequency (Priede, 1983), data storage tags can supply information on e.g. depths and temperature across visibilities and habitats (Stensholt, 2001), and accelerometers can measure and monitor behavioural activities (Broell et al. 2013).

This study evaluates the use of accelerometer tags for indirect observation of piscivore-prey interactions using the ambush predator pike Esox lucius L. 1758 as model species (Craig, 1996, Forsman et al., 2015). Accelerometers have previously been used for different applications in fish behavioural studies, such as the measurement of burst swimming performance (Franklin et al., 2003), activity patterns and energy expenditure (Murchie et al., 2011; Wright et al., 2014), fast start behaviour (Noda et al., 2013), foraging behaviour (Broell et al., 2013; Brownscombe et al., 2014; Kawabata et al., 2014), and mating and spawning behaviour (Tsuda et al., 2006; Whitney et al., 2010). While previous studies have focused on distinguishing between different types of behaviour (i.e. foraging vs. escaping), the present work also evaluates the prospects of applying accelerometry to estimate handling time and prey size in situations where visual observation techniques are logistically impossible. Furthermore, as for pike, fast-start performance and prey capture dynamics have until now only been evaluated using video techniques (Webb \& Skadsen, 1980; Rand \& Lauder, 1981; Frith \& Blake, 1991; Harper \& Blake, 1991).

The accelerometer tag (2.3g (air), 25x12mm, 1.55V silver-oxide button cell (V389, Varta AG)) contained a 3-axis MEMS (Micro-Electro-Mechanical-System) accelerometer sensor and a 2Mbit memory. The accelerometer was set in low-power, "wait-for-movement”-state, and data collection was triggered by an acceleration threshold at $\pm 1.5 \mathrm{~g}\left(\mathrm{~g}=9.82 \mathrm{~m} \mathrm{sec}^{-2}\right)$ for more than $0.2 \mathrm{sec}$, indicative of attack behaviour. The threshold level was established when preparing for the study by 
gradually increasing the threshold until activity events, that were not attacks, no longer triggered the data-logger (in total 5 preliminary trials without prey fish was made). The data logger then continuously recorded acceleration with 12-bit resolution at $100 \mathrm{~Hz}$ during 7 minutes. To avoid accidental triggering of data collection prior to or during tag attachment, the tag was preprogrammed with time of tag activation.

Two pikes (35 and $37 \mathrm{~cm}$ ) were caught by electrofishing in the Lake Krankesjön, southern Sweden, and directly transported to the Ecology building, Lund University. Prior to and during the experiment, pike were individually held in a $200 \times 50 \times 50 \mathrm{~cm}$ aquarium (water depth: $15 \mathrm{~cm}$ ) divided into two equally sized compartments by a sheet of grey PVC. Before each trial, a Velcro tape $(15 \times 7 \mathrm{~mm})$ was glued (Loctite super attack) to the accelerometer tag, and the matching part of the Velcro was glued dorsally to the hard part of the pike head using veterinary glue (3M Vetbond, Fig. 1a) c. 24 hours before activation of the accelerometer tag. Attaching the tag to the head rather than the body allowed for detection of head shaking during prey handling. The accelerometer tag was then carefully attached to the pike by connecting the two matching Velcro parts. This was done approximately three hours prior to the pre-programmed tag activation time, and without any handling or removing of pike from the aquarium. To trigger natural attack behaviour in predatory fish, dead prey is often inadequate (see also Broell et al., 2013). Therefore, an individual life crucian carp Carassius carassius L. 1758 (length: 7.2-12.0 cm) was placed under a non-transparent plastic container $(14 \times 10 \times 20 \mathrm{~cm})$ in one of the short ends of the arena five minutes before tag activation time. Ten minutes later, i.e. five minutes after tag activation, the prey was released by removing the container via a remote pulley system. Activity was monitored and recorded by a surveillance system (Timihillone H264) with a camera (Logitech C920HD) centrally located above the experimental arena. Experiments were performed under evaluation and permission from the 
Malmö/Lund authority for ethics of animal experimentation (licence M36-14), and the use of live prey fish here, were comparable to Broell et al. (2013) and in Kawabata et al. (2014). Furthermore, in order to minimize the potentially harmful treatment of the prey fish, number of predators and the number trials was reduced as much as possible without compromising the conclusions. Also a novel and non-invasive (i.e. skin or flesh penetration) way of attaching the data-logger to the predator was applied.

Data from the accelerometer tag consisted of acceleration along the $\mathrm{x}, \mathrm{y}$, and $\mathrm{z}$ axes recorded at 100 Hz. This three-dimensional data was translated to one-dimensional acceleration using vector norm calculations $M A=\sqrt{x^{2}+y^{2}+z^{2}}$ according to Broell et al. (2013). The accelerometer-based handling time $\left(h_{a}\right)$ was computed as the time period (sec) between the start of the attack that triggered the data logger until $M A$ fell below a threshold value $(\tau)$ of $M A=1.5$. The accuracy of $h_{\mathrm{a}}$ values were validated by comparison with video recorded handling times, where two definitions of handling time were applied when determining observed handling time: time from start of the attack until the pike completely stopped moving $\left(h_{1}\right)$ (this definition allowed unsuccessful attacks to be considered), and time from the start of the attack until the prey was completely engulfed $\left(h_{2}\right.$, only applied to successful attacks). The sensitivity of $h_{a}$ to $\tau$ was evaluated for values of $\tau$ from 1 to 2 in steps of 0.1 . Sensitivity to data logging frequency was evaluated by comparing the $h_{\mathrm{a}}$ values derived from the original data sets to $h_{\mathrm{a}}$ values derived from modified data sets where only every tenth data point was included (simulating a data-logging frequency of $10 \mathrm{~Hz}$ ).

The video recordings confirmed that the accelerometer tag was activated only when the pike attacked a prey, and no attacks took place without activating the tag. In total, eight successful trials 
were completed (5 for pike-1 and 3 for pike-2). Trials were considered unsuccessful if the pike was uninterested in the prey, the video recordings failed, tag pre-programming was erroneous, or the tag detached prior to or during the trial. Video footage revealed that half of the successful trials resulted in a successful attack where the prey was swallowed (both pikes displayed successful and unsuccessful attacks). Unsuccessful attacks were either a single unsuccessful strike with no prey handling, or on two occasions, successful strikes was followed by unsuccessful attempts to hold or turn the prey. The accelerometer tag produced 3D data on movement that were readily transformed to one-dimensional MA for analyses (Fig. 1).

The computerized accelerometer-based handling time $\left(h_{a}\right)$ was significantly correlated to the observed handling time. The best correlation was found for $h_{\mathrm{a}}$ versus $h_{1}$ (Linear regression: $\mathrm{r}^{2}=$ 0.93, $\mathrm{F}_{1,7}=97.28, \mathrm{p}<0.001$ ) and only slightly off the 1:1 relationship (i.e. small underestimation of $h_{1}$ ) (Fig. 2a). However, in the case of the observed handling time fulfilling definition $2\left(h_{2}\right.$, completely engulfed prey) the performance of the accelerometer was poorer. Even though the relationship was still highly significant (Linear regression: $\mathrm{r}^{2}=0.87, \mathrm{~F}_{1,7}=47.1, \mathrm{p}<0.001$ ), the computed $h_{a}$ values were to a much larger extent underestimating the observed handling times (Fig. 2b). The computation procedure of $h_{a}$ was relatively insensitive to the selected threshold ( $\tau$ ) (Fig. 2c) and to a reduction in data-logging frequency from $100 \mathrm{~Hz}$ to $10 \mathrm{~Hz}$ (Fig. 2d). Reducing the frequency did, however, result in loss of handling events lasting less than c. $1 \mathrm{~s}$ (i.e. failed to detect one successful and two unsuccessful attacks at $10 \mathrm{~Hz}$ ). A previous study, differentiating between attack behaviour and other types of standard behaviours, also found that reducing the frequency is potentially problematic (Broell et al., 2013). Lastly, it should be noted that in a few occasions a single brief $M A$ spikes exceeding default $\tau(M A=1.5)$ was observed long after completed prey capture and handling. However, these spikes never exceeded $M A=2$ and lasted less than 0.2 sec, and was therefore easily distinguished from unsuccessful attacks. 
It was not possible to tell apart successful attacks on small prey from unsuccessful attacks, based on accelerometer output. For example, the geometric mean $M A$ during periods of prey handling were negatively related to $h_{a}$, meaning that when unsuccessful attacks produced relatively high levels of $M A$, this had to do with the relatively lower $h_{a}$ of unsuccessful attacks (Fig. 3a,b). The geometric mean MA was highly correlated with average amplitude (i.e Pearson's correlation coefficient: 0.95; $\mathrm{t}=7.63, \mathrm{df}=6, \mathrm{p}<0.002$ ). Hence, the same conclusion was reached when using $M A$ amplitude instead of geometric mean $M A$ as an explanatory factor.

It has previously been demonstrated that accelerometer tags can be applied to discriminate between escape, feeding, and routine behaviour (Broell et al., 2013), determine swimming speed (Thiem et al., 2015), and burrowing behaviour (Almeida et al., 2013). Adding to this list, the potential of quantifying handling time and prey size enables important and interesting possibilities for studying predation and its consequences in aquatic systems.

Automated, numerical estimates of accelerometer-derived handling times $\left(h_{a}\right)$ allows for swift processing of large amounts of data, compared to e.g. video analyses. Estimates of $h_{a}$ corresponded well with observed time from attack until the pike stopped moving $\left(h_{1}\right)$. The remaining part of prey handling was however not detected by the accelerometer, despite high gill movement, why handling time until complete swallowing of prey $\left(h_{2}\right)$ was poorly estimated.

The ability of accelerometry to discern between successful and unsuccessful attacks is limited. Half of the unsuccessful attacks in the present study lasted less than one second, consisting of missed strikes. However, one successful attack also lasted less than one second, involving the smallest prey (72 mm) used in the experiment. This prey was immediately swallowed. All other successful attacks lasted at least eight seconds. On the opposite side one unsuccessful attack lasted more than one second, as the prey was lost relatively late in the handling phase, and this attack could likewise not 
be discriminated from the successful attacks. Failed strikes may thus be identified only in situations where the available prey items are relatively large and uniform in size.

In the majority of published accelerometer studies, the tag was attached to fish using invasive methods such as attachments through the dorsal musculature with different types of sutures or plastic wires (e.g. Franklin et al., 2004; Broell et al., 2013; Almeida et al., 2013) or implanted into the abdominal cavity (e.g. Murchie et al., 2011; Wright et al., 2014; Landsman et al., 2015). In the present study, tags were attached using surgical glue. This approach brought minimal harm to the fish, but the tag remained on the fish in general only 24-72 h (maximum 120h).

Limited data-logging capacity restricts the applicability of accelerometry to short-term measurements, in spite of the acceleration-triggered data recording used here. The high correlation between recordings at $100 \mathrm{~Hz}$ and the simulated estimates for $10 \mathrm{~Hz}$, however, indicates the potential for lower recording frequencies. As long as handling times are not very short (Fig. 2d), recordings at $10 \mathrm{~Hz}$ should suffice for reliable measurements, thereby using less memory space.

In summary, the present study is the first to demonstrate how accelerometer technology can be used to study foraging behaviour in northern pike. The study further indicated that accelerometer technology can be applied to study handling times in settings where video-observation technology is inadequate. In doing so, this study has expanded what is already known about the use of accelerometer technology in studies of foraging behaviour in fishes (Broell et al., 2013; Brownscombe et al., 2014; Kawabata et al., 2014). Although, the method comes with limitations (as discussed above), it still provides the potential for detailing studies of predation in e.g. highly turbid or humic waters, as well as detailed recording of exact acceleration behaviour during prey handling. 
ACKNOWLEDGEMENT: The research was funded by the Danish council of independent research DFF-4002-00114. This report received support from the Centre for Animal Movement Research (CAnMove) financed by a Linnaeus grant (349-2007-8690) from the Swedish Research Council and Lund University.

\section{REFERENCES:}

Almeida, P. R., Pereira, T. J., Quintella B. R., Gronningsaeter A., Costa M. J. \& Costa J. L. (2013). Testing a 3-axis accelerometer acoustic transmitter (AccelTag) on the Lusitanian toadfish. Journal of Experimental Marine Biology and Ecology 449, 230-238.

Broell, F., Noda, T., Wright, S., Domenici, P., Steffensen, J. F., Auclair, J. P., \& Taggart, C. T. (2013). Accelerometer tags: detecting and identifying activities in fish and the effect of sampling frequency. Journal of Experimental Biology 216, 1255-1264.

Brownscombe, J. W., Gutowsky, L. F. G., Danylchuk, A. J., Cooke, S. J. (2014). Foraging behaviour and activity of a marine benthivorous fish estimated using tri-axial accelerometer biologgers. Marine Ecology Progress Series 505, 241-251.

Carpenter, S. R., \& Kitchell, J. F. (1993). The trophic cascade in lakes. Cambridge, UK: Cambridge University Press.

Craig, J. F. (1996). Pike: biology and exploitation. London: Chapman \& Hall.

Forsman, A., P. Tibblin, H. Berggren, O. Nordahl, P. Koch-Schmidt \& Larsson P. (2015). Pike Esox lucius as an emerging model organism for studies in ecology and evolutionary biology: a review. Journal of Fish Biology 87, 472-479.

Franklin, C. E., Wilson, R. S., \& Davison, W. (2003). Locomotion at-1.0 C: burst swimming performance of five species of Antarctic fish. Journal of Thermal Biology 28, 59-65. 
Frith, H. R. \& Blake, R. W. (1991). Mechanics of the startle response in the northern pike, Esox lucius. Canadian Journal of Zoology 69, 2831-2839.

Fryxell, J. M. \& Lundberg, P. (1998). Individual behavior and community dynamics. London: Chapman \& Hall.

Harper, D. G., Blake, R. W. (1991). Prey capture and the fast-start performance of northern pike Esox lucius. Journal of Experimental Biology 155, 175-192.

Jepsen, N., Beck, S., Skov, C., \& Koed, A. (2001). Behavior of pike (Esox lucius L.)> 50 cm in a turbid reservoir and in a clearwater lake. Ecology of Freshwater Fish, 10(1), 26-34.

Jönsson, M., Ranåker, L., Nilsson P. A. \& Brönmark C. (2013). Foraging efficiency and prey selectivity in a visual predator: differential effects of turbid and humic water. Canadian Journal of Fisheries and Aquatic Sciences 70, 1685-1690.

Kawabata, Y., Noda, T., Nakashima, Y., Nanami, A., Sato, T., Takebe, T., Mitamura, H., Arai, N., Yamaguchi, T. \& Soyano, K. (2014). Use of a gyroscope/accelerometer data logger to identify alternative feeding behaviours in fish. Journal of Experimental Biology 217, 32043208.

Kerfoot, W. C. \& Sih A. (1987). Predation: direct and indirect impacts on aquatic communities. Hanover, NH: University of New England Press.

Landsman, S. J., Martins, E. G., Gutowsky, L. F. G., Suski, C. D., Arlinghaus R. \& Cooke S. J. (2015). Locomotor activity patterns of muskellunge (Esox masquinongy) assessed using triaxial acceleration sensing acoustic transmitters. Environmental Biology of Fishes 98, 21092121.

Marsac, F. \& Cayré, P. (1998). Telemetry applied to behaviour analysis of yellowfin tuna (Thunnus albacares, Bonnaterre, 1788) movements in a network of fish aggregating devices. In 

Advances in Invertebrates and Fish Telemetry (Lagardère, J.-P., Bégout Anras, M.-L. \& Claireaux, G., eds.) pp. 155-171. Berlin: Springer.

Murchie, K. J., Cooke, S. J., Danylchuk, A. J. \& Suski, C. D. (2011). Estimates of field activity and metabolic rates of bonefish (Albula vulpes) in coastal marine habitats using acoustic tri-axial accelerometer transmitters and intermittent-flow respirometry. Journal of Experimental Marine Biology and Ecology 396, 147-155.

Nilsson, P. A. \& Brönmark, C. (1999). Foraging among cannibals and kleptoparasites: effects of prey size on pike behavior. Behavioral Ecology 10, 557-566.

Nilsson, P. A., Nilsson, K. \& Nyström, P. (2000). Does risk of intraspecific interactions induce shifts in prey-size preference in aquatic predators? Behavioral Ecology and Sociobiology 48, $268-275$.

Noda, T., Kawabata, Y., Arai, N., Mitamura, H. \& Watanabe, S. (2014). Animal-mounted gyroscope/accelerometer/magnetometer: In situ measurement of the movement performance of fast-start behaviour in fish. Journal of Experimental Marine Biology and Ecology 451, 5568.

Priede, I. G. (1983). Heart rate telemetry from fish in the natural environment. Comparative Biochemistry and Physiology Part A: Physiology 76, 515-524.

Rand, D. M. \& Lauder, G. V. (1981). Prey capture in the chain pickerel, Esox niger: correlations between feeding and locomotor behavior. Canadian Journal of Zoology 59, 1072-1078.

Sih, A., \& Christensen, B. (2001). Optimal diet theory: when does it work, and when and why does it fail? Animal Behaviour 61, 379-390.

Stensholt, B. K. (2001). Cod migration patterns in relation to temperature: analysis of storage tag data. ICES Journal of Marine Science 58, 770-793. 
Thiem, J. D., Dawson, J. W., Gleiss, A. C., Martins, E. G., Haro, A., Castro-Santos, T., Danylchuk, A. J., Wilson R. P. \& Cooke, S. J. (2015). Accelerometer-derived activity correlates with volitional swimming speed in lake sturgeon (Acipenser fulvescens). Canadian Journal of Zoology 93, 645-654.

Tsuda, Y., Kawabe, R., Tanaka, H., Mitsunaga, Y., Hiraishi, T., Yamamoto, K. \& Nashimoto, K. (2006). Monitoring the spawning behaviour of chum salmon with an acceleration data logger. Ecology of Freshwater Fish 15, 264-274.

Whitney, N. M., Pratt, H. L., Pratt, T. C. \& Carrier J. C. (2010). Identifying shark mating behaviour using three-dimensional acceleration loggers. Endangered Species Research 10, 71-82.

Wright, S., Metcalfe, J., Hetherington S. \& Wilson R. (2014). Estimating activity-specific energy expenditure in a teleost fish using accelerometer loggers. Marine Ecology Progress Series 496, 19-32. 
Figure 1. One-dimensional magnitude of acceleration ( $M A)$. Example of a time line of $M A$ values from a succesful attack. The first 200 second of data is presented and the dashed horizontal line represents the threshold value $\tau$ applied in the computerized extraction of handling times $\left(h_{\mathrm{a}}\right)$. In the present example $h_{\mathrm{a}}$ was $22.3 \mathrm{sec}$. The imbedded graphs show the raw accelerations $g$ in three dimensions ( $g$ : $9.81 \mathrm{~m} \mathrm{sec}^{-2}$ ) before the transformation into the one dimensional vector norm.

Figure 2. Validating the accuracy of the accelerometer based handling time. (a \& b) Comparing the computerized accelerometer based handling times $\left(h_{\mathrm{a}}\right)$ to the observed handling times $\left(h_{1}\right.$ and $h_{2}$, see the definitions in Methods and Materials). Data points represent individual trials; successful attacks (black) and unsuccessful attacks (grey). Solid grey lines are regression lines (a: $\mathrm{r}^{2}=0.93, h_{1}$ $\left.=1.25 \times h_{\mathrm{a}}+1.97 ; \mathrm{b}: \mathrm{r}^{2}=0.87, h_{2}=3.13 \times h_{\mathrm{a}}-5.64\right)$ and dashed grey lines are the associated standard errors. The dotted black line is where the points should be aligned if $h_{\mathrm{a}}$ corresponded precisely to the observed handling times (i.e. the 1:1 relationship). (c) Sensitivity to $\tau$. For each threshold the Pearson's product moment correlation coefficient was calculated for the relationship between $h_{\mathrm{a}}$ and $h_{1}$. (d) Comparing $h_{\mathrm{a}}$ derived at $100 \mathrm{~Hz}$ and $10 \mathrm{~Hz}$. The dashed line is where the points should be aligned if $h_{\mathrm{a}}$ values derived from $10 \mathrm{~Hz}$ recordings were identical to $h_{\mathrm{a}}$ values derived from $100 \mathrm{~Hz}$.

Figure 3. Comparing successful and unsuccessful attacks. (a) Density distributions of $M A$ values from all eight trials that was executed successfully, four succesful attacks (red) and four unsuccesful attacks (blue). (b) Geometric mean MA plotted against the computerized handling time $\left(h_{a}\right)$; data include both succesful attacks (red) and unsuccesful attacks (blue). 



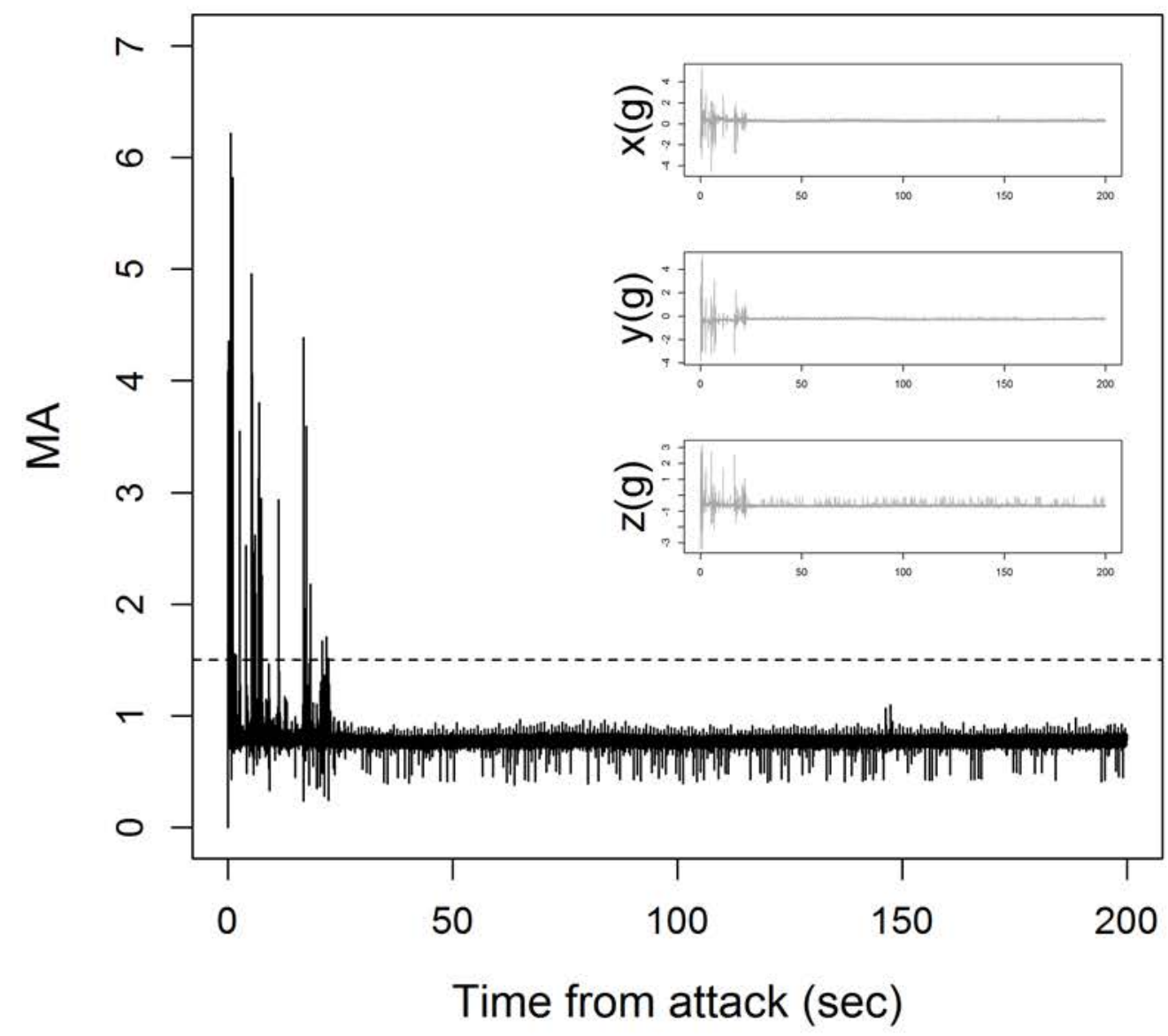



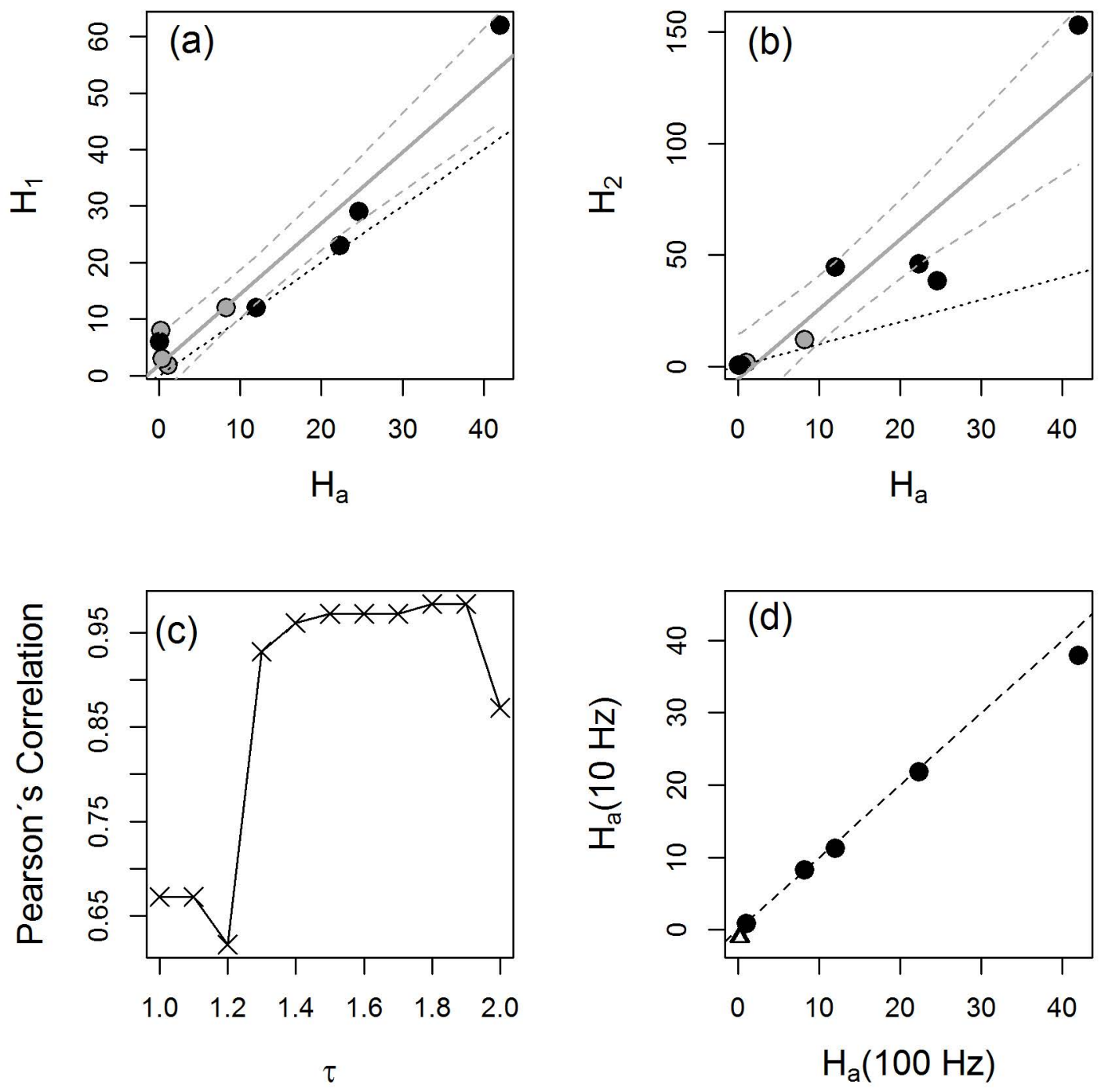

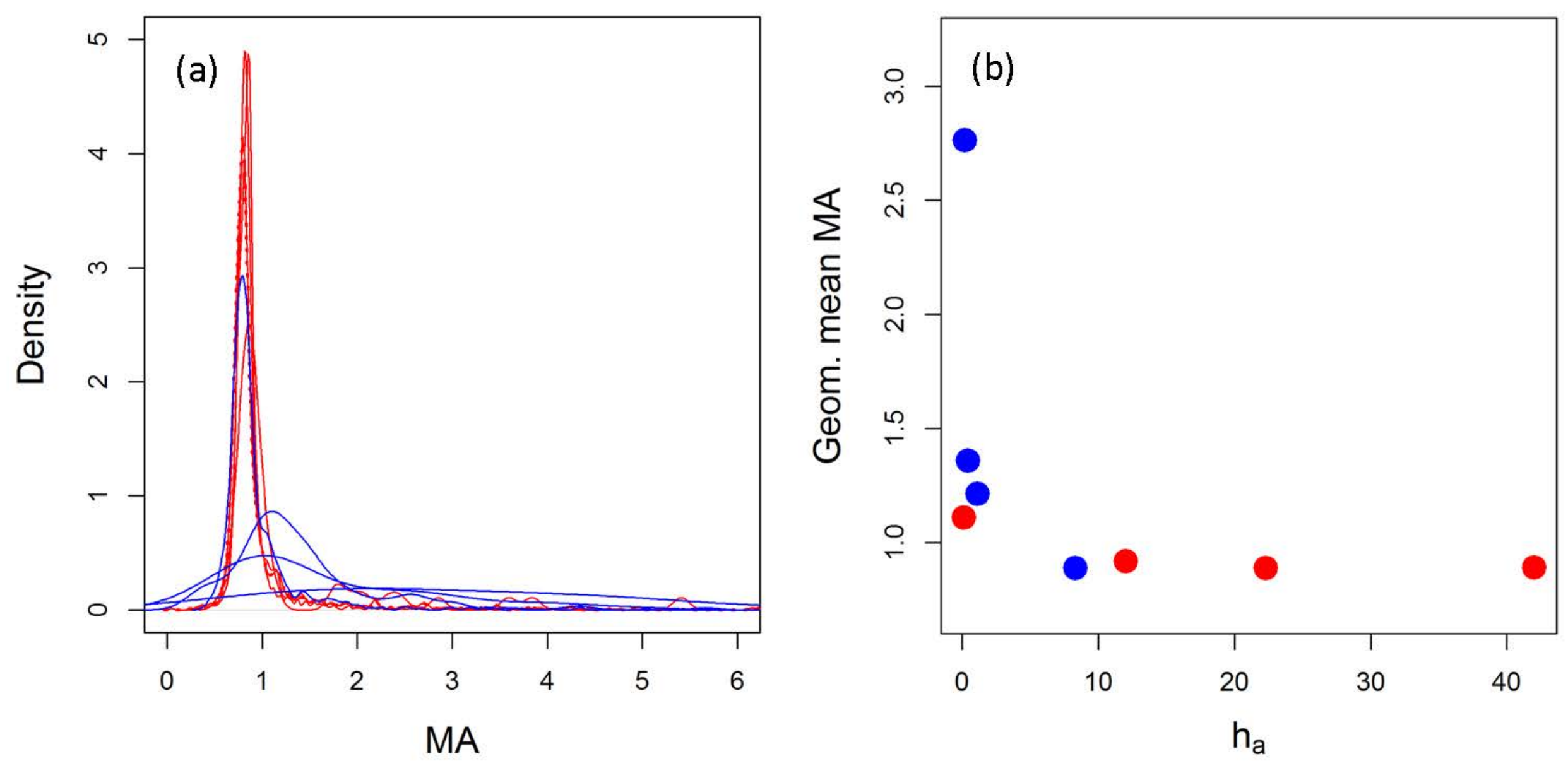